NBER WORKING PAPER SERIES

\title{
UTILIZATION OF INFERTILITY TREATMENTS: THE EFFECTS OF INSURANCE MANDATES
}

\author{
Marianne P. Bitler \\ Lucie Schmidt \\ Working Paper 17668 \\ http://www.nber.org/papers/w17668
NATIONAL BUREAU OF ECONOMIC RESEARCH
1050 Massachusetts Avenue
Cambridge, MA 02138
December 2011

Bitler gratefully acknowledges financial support from the National Institute of Child Health and Human Development (NICHD) (R03 HD046485). Schmidt gratefully acknowledges financial support from NICHD (R03 HD047544). This project was begun while Bitler was at the RAND Corporation. All errors or omissions are our own. We thank Tom Buchmueller, Kitt Carpenter, Stacy Dickert-Conlin, Tracy Gordon, Steven Haider, Mireille Jacobson, Darius Lakdawalla, Kenneth Land, Purvi Sevak, Kosali Simon, two anonymous referees and seminar participants at Michigan State University and the Center for Studies in Demography and Ecology at the University of Washington for helpful comments, and Chris Rogers and Anjani Chandra for their generous assistance with the NSFG data. Corresponding author: Lucie Schmidt, Department of Economics, Schapiro Hall, Williams College, Williamstown, MA 01267, email: lschmidt@ williams.edu, phone (413) 597-3143; fax (413) 597-4045. The views expressed herein are those of the authors and do not necessarily reflect the views of the National Bureau of Economic Research.

NBER working papers are circulated for discussion and comment purposes. They have not been peerreviewed or been subject to the review by the NBER Board of Directors that accompanies official NBER publications.

(C) 2011 by Marianne P. Bitler and Lucie Schmidt. All rights reserved. Short sections of text, not to exceed two paragraphs, may be quoted without explicit permission provided that full credit, including (C) notice, is given to the source. 
Utilization of Infertility Treatments: The Effects of Insurance Mandates

Marianne P. Bitler and Lucie Schmidt

NBER Working Paper No. 17668

December 2011

JEL No. I1

\begin{abstract}
$\underline{\text { ABSTRACT }}$
Over the last several decades, both delay of childbearing and fertility problems have become increasingly common among women in developed countries. At the same time, technological changes have made many more options available to individuals experiencing fertility problems. However, these technologies are expensive, and only $25 \%$ of health insurance plans in the United States cover infertility treatment. As a result of these high costs, legislation has been passed in 15 states that mandates insurance coverage of infertility treatment in private insurance plans. In this paper, we examine whether mandated insurance coverage for infertility treatment affects utilization. We allow utilization effects to differ by age and education, since previous research suggests that older, more educated women should be more likely to be directly affected by the mandates than younger women and less educated women, both because they are at higher risk of fertility problems and because they are more likely to have private health insurance which is subject to the mandate. We find robust evidence that the mandates do have a significant effect on utilization for older, more educated women that is larger than the effects found for other groups. These effects are largest for the use of ovulation-inducing drugs and artificial insemination.
\end{abstract}

\author{
Marianne P. Bitler \\ Department of Economics \\ University of California, Irvine \\ 3151 Social Science Plaza \\ Irvine, CA 96297 \\ and NBER \\ mbitler@uci.edu \\ Lucie Schmidt \\ Dept. of Economics \\ Schapiro Hall \\ Williams College \\ Williamstown, MA 02167 \\ 1schmidt@williams.edu
}




\section{Introduction}

Over the last several decades, delay of childbearing among women in developed countries has become increasingly common. At the same time, the number and share of women experiencing fertility problems have also increased. In 2002, fertility problems affected 7.9 million women in the United States, and the rate of such problems among women aged 15-44 had increased 44\% since 1982 (Chandra and Stephen 2005). Technological changes have made many more options available to individuals experiencing fertility problems. These advances have enabled many women to conceive and deliver their own biological children. However, these technologies are expensive, and only $25 \%$ of health care plans in the United States cover infertility treatment (Mercer 1997). ${ }^{1}$

As a result of these high costs, legislation has been introduced at both the federal and state levels that would mandate coverage of infertility treatment by private insurers. To date, 15 states have enacted some form of infertility insurance mandate, and additional states have ongoing legislative advocacy efforts in this area. Much of the rhetoric from supporters surrounding passage of the mandates focuses on expanding access to those who could not afford treatment otherwise (New York Times 2001: www.resolve.org). On the other hand, opponents argue that these mandates and other health insurance regulations force insurers to offer benefits for services that people might not want or be able to afford, suggesting that mandates like these may not lead to increases in utilization and perhaps might have other adverse effects. Given the

\footnotetext{
${ }^{1}$ Although not all fertility treatments are expensive, the less expensive treatments are generally more likely to be covered by health insurance in the absence of mandates, in part because some of them can legitimately be billed under categories covered by most insurance plans.
} 
continued interest in these types of mandates by policy makers as well as the current focus on health care reform, understanding whether these types of private insurance market regulations affect utilization of health care services, and if so, for whom, is critical. ${ }^{2}$

In this article, we use data from the National Survey of Family Growth (NSFG) to examine whether infertility insurance mandates affect utilization. We allow utilization effects to differ by age and education, since previous research suggests that older, more-educated women should be more likely to be directly affected by the mandates than younger women or lesseducated women, both because they are at higher risk of fertility problems and because they are more likely to have private health insurance, which is subject to the mandate.

We contribute to the literature about fertility determinants and, in particular, infertility treatment in several ways. Our research uses panel data techniques, and our data span years both before and after the adoption of most mandates, allowing us to use variation in adoption timing across states and years, and to control for unobservable differences in utilization across states and over time using state and year fixed effects. This cannot be done in studies using clinic data reported to the Centers for Disease Control (CDC) because these data are unavailable for the years before most mandates were in effect. Our data allow us to examine effects on the use of all infertility treatments, while the CDC data examine only the use of assisted reproductive technologies (ART) like in vitro fertilization (IVF), which compose only a small fraction of infertility treatments received. Our data also allow analysis of a wide range of specific types of

\footnotetext{
${ }^{2}$ A number of studies (Buckles 2006; Bundorf et al. 2008; Bitler 2010; Schmidt 2007) have illustrated an effect of these mandates on births or birth outcomes, suggesting that there is likely to be a utilization effect as well. We discuss these studies in detail in the third section of this article.
} 
non-ART infertility treatments, including ovulation-inducing drugs, artificial insemination, and testing of both partners. Finally, we focus on the use of treatments at the population level and can therefore produce estimates of the effect of mandates on the utilization of treatments by all women, not just those whose treatments result in live births. This could be a substantial share of the additional treatments induced by the mandates.

We find robust evidence that the mandates have the largest effect on utilization of infertility treatment for highly educated, older women, and that these effects are statistically significant. By contrast, most of the impacts for other groups are smaller in magnitude and are insignificant. In addition, the pattern of results confirms expectations about the types of treatments that should be impacted: relatively expensive treatments that would be more difficult to pay for out of pocket and would not be covered unless infertility treatment was covered. Specifically, we find that mandates lead to statistically significant and relatively large increases in the use of ovulation-inducing drugs and, in some specifications, in the use of artificial insemination. These results suggest that private insurance regulations requiring that insurers cover specific treatments have the ability to alter utilization in the context of infertility treatment.

\section{Mandated Insurance Benefits}

Over the past 30 years, state-level mandated health insurance benefits have grown in popularity as a means of trying to regulate the private health care system. Currently, well over 2,000 statemandated benefits are in effect (Bunce and Wieske 2010). These laws require the coverage of specific health services or coverage of the services provided by specific types of providers. Advocates of the laws appeal to unmet need, while opponents argue that such laws force firms to buy coverage for services their employees value less than their marginal cost, potentially leading to higher rates of uninsurance. 
The primary economic efficiency argument in favor of mandated benefits for specific illnesses and conditions relies on asymmetric information between patients, insurers, and firms. If such asymmetric information exists, this could lead to adverse selection in the health insurance market (see, e.g., Rothschild and Stiglitz 1976). Mandates could also cause detrimental effects, if mandating benefits reduces employment or health insurance coverage. ${ }^{3}$ However, research on the effects of mandates on health insurance coverage (Gruber 1994) and labor market outcomes (Kaestner and Simon 2002) has found little effect overall.

Proponents of mandated insurance benefits aim to affect utilization of health services and, ultimately, health outcomes. However, recent evidence on the effects of mandates is mixed, suggesting that mandates may increase utilization for some groups but have little impact on other outcomes. Bao and Sturm (2004) and Pacula and Sturm (2000) found no significant effects of mental health parity legislation (considered to be a "high-cost" mandate) on utilization of mental health services among the privately insured, but found some evidence that mandates increase utilization of services among those with poor mental health. Recent work on early postpartum discharge laws (Liu et al. 2004) found a positive significant effect of these laws on length of hospital stays. Other work suggests that mandates for breast cancer screenings have led to a significant increase in annual mammography rates (Bitler and Carpenter 2011).

Several possible explanations have been considered for the lack of consistent effects found in much of the existing literature. First, state-level mandated benefits will not affect all individuals within a state. Mandates apply only to individuals (and their covered dependents) who have private insurance, and should affect only individuals employed by firms that do not

\footnotetext{
${ }^{3}$ Effects on health insurance coverage could result either from reduced offering of insurance or reduced take-up.
} 
already cover such benefits. In addition, the Employee Retirement Income Security Act of 1974 (ERISA) preempts specific state regulation of self-funded insurance plans provided by privatesector employers. As such, it is possible that legislation may not affect enough individuals for researchers to discern an impact if looking at the entire population. For example, Liu et al. (2004) found that the effect of drive-through delivery laws has been blunted by ERISA. Furthermore, many mandates potentially affect only a smaller subgroup of the population (e.g., mental health mandates affect those in need of mental health services), and this may not be the same subgroup that has private insurance. Even if the subgroup consists of individuals who are privately insured at high rates, if they are a small share of the population or if the effect for them is small, it might be easy to conclude that the overall policy had little or no significant effect on the basis of regressions that constrain the policy to have the same effect for everyone. ${ }^{4}$

Second, it has been suggested that state mandate laws may not be binding (Gruber 1994). Some evidence suggests that benefits are similar in firms in states that mandate relative to firms in states that do not mandate, as well as in firms that self-insure relative to firms that are fully insured within mandate states (Acs et al. 1996; Gruber 1994; Jensen et al. 1998), although much of this evidence is dated or relies on employee rather than firm data. However, this is not usually the case for infertility treatment, which is rarely covered in the absence of mandates.

Firms may also manipulate the combination of benefits and wages they offer to attract or retain particular types of employees (e.g., Gelbach et al. 2009; Oyer 2008). For example, if being

\footnotetext{
${ }^{4}$ Intuitively, if the effect of the policy is small for the relevant group relative to the residual variance and zero (or close to zero) elsewhere, or if the subgroup is small, a test for an overall policy effect is more likely than a test for a subgroup-specific policy effect to fail to reject a null hypothesis of zero effect.
} 
an employee who values infertility treatment is positively correlated with productivity, then even self-insured firms may choose to offer their employees insurance coverage that includes infertility benefits. If mandates do not affect the benefits offered by firms, then they would not be expected to affect utilization of services or health outcomes unless they resulted in premium changes that altered take-up decisions. Finally, there are political economy issues associated with the passage of mandates. If employers do not expect a mandate to have a large impact on health care utilization and costs, they are less likely to oppose the legislation (Bao and Sturm 2004).

Overall, the theoretical predictions and empirical findings from previous work are mixed; thus, it is an empirical question whether infertility insurance mandates will have real effects on utilization of services.

\section{Infertility Treatment and Infertility Insurance Mandates}

In order to understand the potential effects of infertility insurance mandates, it is necessary to understand infertility and its treatment. Today, treatment for infertility tends to follow a hierarchical progression, although not all couples progress neatly through all stages of treatment. In general, the first stage of treatment is a diagnostic workup, involving a thorough examination of each partner's reproductive organs and their circulatory, endocrine, and necrologic functions. Couples who initiate treatment begin at Level I, which involves initial ovarian stimulation with clomiphene citrate for up to six cycles (taking at least 6 months). Level II involves the use of exogenous gonadotrophins (another drug used to stimulate ovulation), with or without intrauterine insemination (IUI), for up to six cycles; and Level III involves assisted reproductive technologies such as in vitro fertilization (IVF), for up to four or more cycles. As a result, many couples who reach Level III will also have received Level I and II treatments along 
the way. ${ }^{5}$ Of couples who begin treatment, more than $80 \%$ of those who proceed through all the steps are likely to conceive (Gleicher 2000). Even for couples who are successful with their first cycle of IVF, the process can take 2-3 years.

Infertility services can be quite expensive and are not covered by many insurance plans. Hormone therapy can range from $\$ 200-\$ 3,000$ per cycle. Tubal surgery can range from $\$ 10,000-\$ 15,000$, requires a hospital stay, and poses a high risk of complication (RESOLVE 2003). The average cost of an IVF cycle in the United States is $\$ 12,400$ (American Society of Reproductive Medicine (ASRM) 2003), and Neumann et al. (1994) calculated that the cost per successful delivery through IVF ranged from $\$ 44,000$ to $\$ 211,940$ in 1992 dollars, depending on the cause of infertility, the mother's age, and other factors.

As a result of these high costs, one way that access to infertility treatments has been expanded in the United States is through legislative action. The first state-level infertility insurance mandate was enacted by West Virginia in 1977. Since that time, 14 other states have passed mandates, and additional states have ongoing legislative advocacy efforts in this area. Table 1 contains a list of states that have passed mandates, along with the year the mandate passed. The table shows that there is considerable variation in both the timing of the mandates and in the types of states that have passed mandates, with the list including both small and large states as well as states from all U.S. regions. Some mandates are mandates "to cover," and

\footnotetext{
${ }^{5}$ This progression is also evident in our data from the NSFG. For example, of the women in the NSFG who reported receiving IVF, about $80 \%$ reported receiving male and female testing, $65 \%$ also received ovulation-inducing drugs, and $46 \%$ also reported artificial insemination. These and other numbers are reported in Table 2 and are discussed in greater detail in the Data and Methodology section.
} 
require that health insurance companies provide coverage of infertility treatment as a benefit included in every policy. Less commonly, states have enacted mandates "to offer," and require only that health insurance companies make available for purchase policies that cover infertility treatment. Finally, some mandates exclude coverage of IVF. ${ }^{6}$ Although only 15 states had mandates in place during our sample period, these mandates were enacted in a number of large states and therefore affect an increasingly large fraction of the population. In 1981, less than 1\% of the population resided in a state affected by the mandates, compared with $47.2 \%$ in 2003 .

Previous research has examined the impacts of these insurance mandates on fertility. Schmidt (2007) used Vital Statistics Detail Natality Data (DND) and census population counts to examine the effects of the mandates on first-birth rates, and found that mandates increase firstbirth rates among older women by $19 \%$. Buckles (2006) used the DND and found that the insurance mandates increased the number of children per birth. Bitler (2010) used the DND and found an increase in the probability that infants born to older mothers are twins, and a larger increase in the probability that they are mixed-sex twins. Bundorf et al. (2008), also using the DND, provided evidence of an increase in deliveries and an increase in multiple births for older women. This previous literature has focused on older women in states with mandates, in part because these women are more likely to be infertile and demand treatment and in part because any mandate effects operating through private insurance markets must affect women who are privately insured at high rates. ${ }^{7}$

\footnotetext{
${ }^{6}$ For additional detail on the mandates, see Schmidt (2005).

${ }^{7}$ An alternative possibility is that the mandates could have a larger impact for younger than older women (conditional on needing treatment), since older women are more likely to have higher incomes and therefore presumably have lower price elasticities of demand. Chambers et al.
} 
These studies provide consistent evidence that the infertility mandates have had significant fertility effects for older women, implying that the mandates have had utilization effects as well. However, examining these utilization effects directly is important for a number of reasons. First, it would allow confirmation of the previously discovered fertility effects with a different data source. More importantly, examining utilization effects could provide information on the types of treatment that women receive. Some treatments are relatively high cost, while others are less expensive. Some are more likely to be used by the women with the lowest fecundity (e.g., IVF), while others may be used more broadly. Some may legitimately be covered by health insurance even if infertility treatment is excluded (e.g., tubal surgery). Mandates could also cause women to progress through the levels of treatment more quickly than they would if they faced expenses out of pocket. Addressing these possibilities is an important step toward understanding the relevant costs and benefits of the insurance mandates. Finally, studying the effects of the mandates on utilization provides information on use of treatments that do not result in live births, which would be undetectable using birth records such as the DND. ${ }^{8}$

(2009) reported price elasticities of demand for IVF from developed countries but did not calculate the elasticities by age or education. However, at the same time, younger women face a longer time frame before they become unable to have a child for biological reasons after menopause, and they also may be less likely to be aware of their possible impaired fecundity. In addition, for two women with the same biological ability to have children at each age, the younger woman will still be less likely than the older woman to have difficulty conceiving because of the age-related decline in fecundity.

${ }^{8}$ Data on timing of the first fertility visit is available only for the 1995 and 2002 NSFGs. Fully $30 \%$ of all women who ever used ovulation-inducing drugs, $42 \%$ of women who used artificial 
The majority of the previous work on the impacts of the mandates on utilization of services has focused on a single measure of utilization: cycles of assisted reproductive technologies (ARTs) (e.g., Bundorf et al. 2008, 2009; Hamilton and McManus 2005; Henne and Bundorf 2008; Jain et al. 2002). ${ }^{9}$ ARTs include all procedures that combine egg and sperm outside the body, such as IVF. These previous studies used data from a combination of two sources: congressionally mandated clinic reports of success rates for ART cycles, and reports of such treatments collected by the American Society for Reproductive Medicine (ASRM), a provider group. These studies found consistent evidence that mandates are associated with increased rates of IVF utilization. Unfortunately, these data have two important limitations. First,

insemination, and 54\% of women who ever used IVF have never had a live birth (Authors' tabulations of NSFG data). While some share of these women are likely still getting treatment and may go on to eventually have a live birth, others most likely have been unable to conceive or carry a live birth to term even with treatment. This suggests that a large share of potential treatments might be missed in data that look only at live births. If we limit this calculation to women who had no first birth after their first infertility treatment and have not had a visit for infertility treatment in the past year, assuming that these women might be the most likely to have given up trying to conceive, we see that $15 \%$ of those getting any medical help to get pregnant, $16 \%$ of those who took ovulation-inducing drugs, and $20 \%$ of those getting insemination fall into this category.

${ }^{9}$ One exception is a recent study by Mookim et al. (2008), who used claims data from a set of large firms in 2001-2004 to look at a variety of treatment uses and their impact on outcomes. While they, too, captured a large set of treatments, as with the research on use of ART, their data are from a post-mandate period for most states. 
when these two data sources are combined, they extend back only to 1987 or so, a period after many of the mandates were enacted. Because these previous studies did not have pre-mandate data on utilization, they could not control for unobserved differences in utilization across states that may be correlated with but not caused by the mandates. In addition, their analyses were limited to ART procedures. Despite being very expensive, ARTs compose only $5 \%$ of all infertility treatments (ASRM 2003). In our own NSFG data, only 2\% of women who ever had any infertility treatment reported using IVF.

In earlier work (Bitler and Schmidt 2006), we used the NSFG to examine racial/ethnic and socioeconomic disparities in infertility and in utilization of infertility treatment. We found that fertility problems are more likely among nonwhite and less-educated women, but that infertility treatment is utilized much more heavily by white and college-educated women. We then looked at the insurance mandates and found no evidence that they have mitigated these racial/ethnic or socioeconomic disparities in utilization of infertility treatment. In fact, we found no effect of these mandates on utilization of infertility services for the overall population of women aged 15-44, or for subgroups of college-educated women, older women, or white women. We did report that a model with a three-way interaction between high education, any mandate, and age at least 30 leads to a statistically significant marginal effect of 4.6 percentage points on any use of infertility treatment or medical help to prevent miscarriage. However, this result was included only to bolster an argument about power for explaining disparities and was not explored in any detail.

In this article, we use the NSFG to comprehensively explore utilization effects of the infertility insurance mandates. The timing of the NSFG includes years spanning the passage of the infertility mandates, and therefore allows us to control for unobservable differences in 
utilization across states that are constant over time. We replicate our earlier (Bitler and Schmidt 2006) finding that older, more-educated women exhibit an increase in utilization as a result of the mandates. We then use the rich detail on types of infertility treatments available in the NSFG to examine the robustness of these findings. First, we look at whether mandates primarily affect use of medical help to get pregnant versus use of medical help to prevent miscarriage. Mandates should have a larger impact on the use of medical help to get pregnant and should have only indirect effects on the use of medical help to prevent miscarriage, which was likely covered by existing insurance. These indirect effects could result if mandates induce greater use of treatments among women who become pregnant after treatment and then later are at high risk for miscarriage. Then, we look at the association between the mandates and the use of specific treatments that are costly and might plausibly be affected by the mandates. The NSFG provides information on a wide set of possible treatments, so we are able to examine a wider range of specific infertility treatments than those about which information is available in most other data sets.

There are several reasons that older, highly educated women should be particularly strongly affected by infertility mandates. The first is related to demand for treatment. In order to desire treatment for infertility, one has to seek to become pregnant and be unsuccessful. ${ }^{10}$ Over the last several decades, increases in female labor force participation and educational attainment have been accompanied by delays in childbearing. The average age at first birth increased from 21 years in 1970 to 25 in 2000 (Mathews and Hamilton 2002), and differences in age at first

\footnotetext{
${ }^{10}$ Medically, a woman is defined to be infertile after one year of unsuccessful efforts to become pregnant if she is younger than 35 , or after six months of unsuccessful efforts if she is 35 or older.
} 
birth by educational category have been even more striking. College-educated women are more likely to delay childbearing, perhaps in part to reduce the motherhood wage penalty associated with childbearing (e.g., Blackburn et al. 1993; Miller 2011). As women wait longer before attempting to have children, the age at which women's fertility problems are first discovered will rise.

In addition, according to the clinical and demographic literature, age is independently associated with difficulty conceiving and carrying a pregnancy to term (Menken 1985; Weinstein et al. 1990). Older women are significantly more likely to experience fertility problems and to seek help for these problems (Stephen and Chandra 2000; Wright et al. 2003). For example, in 2002, women 30 and older accounted for almost $89 \%$ of all assisted reproductive technology procedures performed in the United States.

The second reason to expect any effects to be stronger among older, highly educated women is that these state-level mandates generally legally apply only to persons with private health insurance. ${ }^{11}$ Our own calculations from 2003 Medical Expenditure Panel Survey data suggest that $14 \%-19 \%$ of private-sector employees enrolled in employer-provided insurance in the United States were in firms to which these infertility insurance mandates applied (firms with

${ }^{11}$ However, since ERISA exempts self-insured plans, having private insurance is a necessary but not sufficient condition for having a mandate affect one's coverage of infertility treatment. Unfortunately, no publicly available data allow us to test whether older, highly educated women are more likely than younger or less-educated women to have private insurance from a plan that does not self-insure. A recent study using firm-based data suggests that about $50 \%$ of covered workers in 2001 were in plans that were self-insured, and that this number had declined slightly since 1993 (Gabel et al. 2003). 
at least one non-self-insured plan; figures derived from Agency for Healthcare Research and Quality (AHRQ) 2005). Older, highly educated women are more likely to have private coverage (through their own employer, a spouse's employer, or an individual plan) than are other women. During the calendar year $2002,85 \%$ of women 30 and older with some college education were covered by a private health insurance plan, while only $64 \%$ of women with at most a high school diploma had such coverage (authors' tabulations based on the 2003 March Current Population Survey). ${ }^{12}$ We expect the effects to be largest and relatively concentrated among this subgroup of older, highly educated women in states with mandates. Mean reports of ever having had any medical help to get pregnant (discussed later) support this prediction, with rates for older women with some college being 1.5 times as large as for older women with no college $(0.168$ versus $0.112)$ and 3.5 times as large as for younger women with or without some college ( 0.168 versus $0.048)$.

\section{Methodology and Data}

${ }^{12}$ This same group of women is also likely to have higher levels of income with which they could presumably pay for infertility treatments out of pocket. However, the median family income for white women with at least some college education in 2001 was approximately $\$ 58,000$, which likely would not easily enable a family to pay for infertility treatments out of pocket, given estimates that suggest that the median cost per live delivery resulting from IVF is $\$ 56,419$ (Collins 2001). More recent estimates from a comparison of developed countries suggest that the gross cost of a single IVF cycle as a percentage of annual disposable income was highest in the United States, at 50\%, compared with, for example, 12\% in Japan (Chambers et al. 2009). 
We pool individual-level data from the 1982, 1988, 1995, and 2002 rounds of the NSFG to see whether utilization of infertility treatment is heavier in states with infertility insurance mandates. Each wave of the NSFG surveys a nationally representative sample of women aged 15-44 on their fertility and marital histories. The NSFG is the only nationally representative source of individual-level data that asks detailed questions on infertility treatment, and the only publicly available source of data that provides information on infertility treatments that do not involve ARTs. ${ }^{13}$ It allows us to examine changes in utilization of treatments that do not result in live births. In addition, it is the only data set with information on infertility treatments that spans the years both before and after the mandates were passed, which is essential when trying to control for unobservable state differences in treatment propensities. We use the restricted-access version of the NSFG data with state identifiers, and merge information on state infertility insurance mandates with the NSFG data.

Our first dependent variable of interest for this analysis is an indicator for whether the woman has ever obtained infertility treatment. Women are coded in the NSFG as ever having obtained infertility treatment if they reported either having obtained medical help to get pregnant or having obtained medical help to avoid a miscarriage (or both). We first look at the aggregate variable, but we then separate it into the two components, since we expect insurance mandates to affect the two variables differently. If there are utilization responses that are clearly due to the mandates, we would expect them to affect use of medical help to get pregnant more than use of

\footnotetext{
${ }^{13}$ Claims data, such as those used by Mookim et al. (2008), also include information on various treatments, but only for women with insurance that reimburses them for it. As far as we know, such data are also not publicly available for a period before the mandates.
} 
medical help to prevent miscarriage (which was likely to be covered in the absence of a mandate and should only indirectly respond to the mandates).

We then decompose the "obtained any medical help to get pregnant" variable by type of treatment. Women were asked about various specific types of treatment as well as about some “other treatment." Thus, this category includes some relatively costly therapies that are almost exclusively used for infertility treatment—-that is, ovulation-inducing drugs, artificial insemination, and IVF. But it also includes other medical procedures that are less expensive or might plausibly have been covered without mandates, including testing of the respondent or her partner, surgery for blocked tubes, and "other treatment" (which varies by year of the survey but includes treatment for endometriosis or fibroids, advice, and "other treatment not listed" categories). At least one of these other procedures, tubal surgery, is increasingly considered by the medical profession to be a less attractive substitute for IVF (Gocial 1995; Practice Committee of the American Society of Reproductive Medicine 2008). Other evidence suggests that even in the absence of insurance coverage for infertility treatment, some treatments may be paid for by insurers under alternate billing codes (Blackwell and Mercer 2000; Jones and Allen 2009). We expect the mandates to increase use of ovulation-inducing drugs, artificial insemination, and IVF more than they increase use of the other therapies both because these are more expensive and because these are harder to surreptitiously bill for in the absence of insurance coverage for infertility treatment. However, it is likely that capturing effects on IVF will be challenging in an individual-based sample like the NSFG because of sample size: only $0.2 \%$ of the women in all waves of the NSFG reported receiving IVF.

As would be expected given the hierarchical nature of the typical treatment ladder discussed in the previous section, many of these women are obtaining more than one treatment, 
and the NSFG allows women to check more than one treatment in their responses. This use of multiple treatments is reported in Table 2. Panel A of Table 2 shows the share of respondents who received each of the specific types of infertility treatments (columns 1-6), or received some other treatment (column 7), first among all women and then among all women who received medical help to get pregnant. For women who received the specific treatments listed in columns 1-6, Panel B reports the share who also received the other treatments listed by row. For example, column 1 indicates that among women who used ovulation-inducing drugs, $17 \%$ also had artificial insemination, $3 \%$ had IVF, $62 \%$ had the woman tested, $52 \%$ had the man tested, $18 \%$ had tubal surgery, and 69\% had some other treatment. Among women who had artificial insemination, $10 \%$ had IVF, $71 \%$ used ovulation-inducing drugs, $85 \%$ had the woman tested, $75 \%$ had the man tested, and $78 \%$ had some other treatment. The overlap of treatments suggests that we might observe increases among all treatments, even those that might plausibly have been partly paid for by insurance that did not cover infertility treatment (e.g., see Blackwell and Mercer 2000; Jones and Allen 2009).

Given how common the use of multiple treatments is in our sample, we wanted to isolate those who reported "any other treatment" but did not also receive one of the six treatments specifically identified. To do this, we created an alternative residual "other treatment" variable for women who reported medical help to get pregnant but did not receive any of the treatments listed in columns 1-6. Means for this residual "other treatment" variable are reported in column 8 , and this residual "other treatment" is the one for which we report regression results. Our hypothesis about this second "other treatment" variable is the most clear - that is, that reports of it should not increase significantly with the mandates. 
One potential issue with the outcome measures used here relates to the distinction between stocks and flows. Conceptually, we would like to measure the effect of the mandates on the likelihood that a woman utilizes infertility treatment in a given year. However, the variables we are using examine whether the respondent has ever received infertility treatment and therefore measure the stock of women who have received treatment. Use of a stock measure in state-year fixed-effects design can lead to overstating the magnitude of the effect, with the magnitude of the overstatement increasing with the length of the post-treatment implementation reporting period. However, all of our variables are binary indicators of ever using particular treatments. If these mandates were only to increase the level of use (intensive margin) and had no effect on whether a woman ever used any treatment (the extensive margin), our binary indicator variables would not show an increase. Thus, even if mandates affect the number of women who receive treatment in a given year, the stock of women who have ever received treatment may be changing much more slowly. This suggests both that the true effects of the mandates on contemporaneous use of treatments may be larger than the estimates we present and that our power to find significant effects may be reduced. These two competing effects imply that bias in the magnitude of our estimates could be either upward or downward. Despite these possible limitations, our analysis provides an important contribution to the literature, since, as detailed in the previous section, it allows us to learn more about the extent to which these mandates affect the use of all treatments (not simply ARTs) and uses an identification strategy that can control for unobservable differences across states in utilization.

Table 3 contains summary statistics for our treatment variables for all women, as well as by age group (under 30 versus 30 and older) and by completed education (no college versus at least some college). While about $10 \%$ of women aged 15-44 have ever obtained medical help to 
get pregnant, this varies dramatically by age and educational status. Only about $5 \%$ of women under age 30 have obtained such treatment, while $11.2 \%$ of women 30 and older with no college and $16.8 \%$ of women 30 and older with some college have obtained such treatment. These patterns hold for the aggregate "had treatment to help get pregnant" variable and for virtually every individual type of infertility treatment. Older women with at least some college are 3.5 times as likely as women under age 30 with some college to have received medical help to try to get pregnant $(16.8 \%$ versus $4.8 \%)$. They are about 5 times as likely as younger women to have been treated with ovulation-inducing drugs ( $6.5 \%$ versus $1.4 \%), 9$ to 19 times more likely to report artificial insemination ( $1.9 \%$ versus $0.1 \%$ or $0.2 \%$ ), and 25 times more likely to report IVF $(0.49 \%$ versus $0.02 \%) .{ }^{14}$ The differences in use by education category among older women are still large, although not as dramatic as the differences by age. Older women with more education were 1.9 times more likely than older women with less education to have ovulation-inducing drugs, testing of the female, or testing of the male; 2.4 times more likely to have insemination; and 6.1 times more likely to have IVF.

Next, we turn from the simple means to multivariate regressions. We estimate linear probability models of the following form ${ }^{15}$ :

\footnotetext{
${ }^{14}$ Simple $t$ tests lead us to reject equality of means across group (high/low education by age 30 and older/age under 30) for all of the outcomes we examine, with $p$ values all well below .01 . ${ }^{15}$ All of our dependent variables are binary indicators, and some of their averages are small, which might lead to concerns about the use of least squares. We verified that these results are robust to functional form by estimating the corresponding logistic regressions and calculating marginal effects. Results are quite similar in both magnitude and statistical significance and are available from the authors on request.
} 


$$
\begin{aligned}
& \text { treatment }_{i s t}=\alpha+\beta_{1} \text { mandate }_{\text {st }}+\beta_{2}\left(\text { age } 30+_{\text {ist }}+\beta_{3} \text { somecoll }_{\text {ist }}\right. \\
& +\beta_{4}\left(\text { mandate }_{\text {st }} \times \text { age } 30+_{\text {ist }}\right)+\beta_{5}\left(\text { mandate }_{\text {st }} \times \text { somecoll }_{i s t}\right)
\end{aligned}
$$

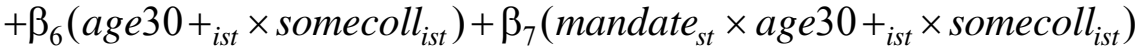

$$
\begin{aligned}
& +X_{i s t} \delta+Z_{s t} \lambda+\gamma_{s}+v_{t}+\varepsilon_{i s t} \text {. }
\end{aligned}
$$

Treatment represents the treatment categories reported by NSFG respondents and described earlier. We first look at whether a woman reports ever having infertility treatment. We then categorize these reports into two groups: reports of receiving any medical help to get pregnant, and those of receiving any medical help to avoid a miscarriage. (Note that these two measures are not mutually exclusive.) We then analyze the types of treatment received, looking specifically at ovulation-inducing drugs, artificial insemination, IVF, male and female testing, tubal surgery, and the residual other treatment category (treatment to get pregnant that is not one of those specific treatments listed).

For the reasons previously outlined, we expect that the mandates will have the largest impact on older, college-educated women, since they are the group at higher risk for fertility problems and the group most likely to have private health insurance. ${ }^{16}$ Thus, our key estimated effect, $\beta_{7}$, is the coefficient on the three-way interaction between the woman's state having an infertility insurance mandate, the woman's age being at least 30, and the woman having attained at least some college. We also control separately for mandate, age, and education effects, as well as all two-way interactions between mandate, age, and education. Our regressions include both state and year fixed effects. ${ }^{17}$ Finally, we look to see if there are differences in utilization effects

\footnotetext{
${ }^{16}$ We cannot observe private insurance coverage in all waves of our data and likely would not want to use it as a control in any case because it could conceivably respond to the mandates.

${ }^{17}$ Note that if there are offsetting effects in some groups, or small effects in groups that are a larger share of the population, it might be difficult to detect these larger effects for highly
} 
for states with cover mandates versus states with offer mandates and for IVF versus non-IVF mandates, with the expectation that the significant effects should be larger for states with cover mandates relative to those with offer mandates and for IVF relative to no-IVF states. ${ }^{18}$

We control for a number of individual-level characteristics, including age, race/ethnicity, educational attainment, and whether the woman lives in an urban area. We also control for a number of time-varying state-level characteristics, such as the share of the population that is black and the share Hispanic, the Medicaid eligibility threshold for a pregnant woman, the real

educated women when pooling all the data and identifying the policy in a differences-indifferences setting. We have examined this by estimating straight differences-in-differences regressions where the mandate variables are only allowed to vary by state and year. In these analyses, the effects for the overall population are small in magnitude compared with those reported in Tables 4 and 5 for the highly educated older women, and are statistically insignificant. We have also estimated regressions restricted to various subgroups of the population defined by age (education), in which we interact the mandate with education (age). These results are all reported in an online appendix at Bitler's website.

${ }^{18}$ Previous work by Bundorf et al. (2008) and others has focused primarily on categorizing mandates as "cover including IVF" and "cover excluding IVF." We do not use this as a primary specification in part because of concerns raised in a recent study by Conley and Taber (2011) about overrejection in differences-in-differences models with state-level clustering when only a few states change treatment status (only three states are "cover excluding IVF" states). We estimated this as an alternate specification, and the results for ovulation-inducing drugs are significant for "cover including IVF" mandates and slightly larger (0.03 versus 0.024$)$ than the estimated effect for "cover excluding IVF" mandates. 
maximum AFDC/TANF benefit for a family of four, real median income for a family of four, the unemployment rate, the employment growth rate, the share of the population under the federal poverty level, and the share of births to unmarried women. Existing literature suggests that these characteristics might be correlated with fertility behavior (See, for example, Bitler and Zavodny 2010, Dehejia and Lleras-Muney 2004, Schmidt 2007).

We weight the data to be population-representative, and we report heteroskedasticityrobust standard errors clustered at the state level. ${ }^{19}$ We estimate these regressions on the sample of women who have had sex and are past menarche. We also tested to see whether our results are driven by endogeneity of the passage of mandates by including leads of the mandate variables in our specifications; these leads are not statistically significant.

\section{Results}

Table 4 reports the ordinary least squares (OLS) regression results for utilization of infertility treatment as a function of state-mandated infertility insurance. Column 1 replicates our previous findings (Bitler and Schmidt 2006) and presents results for whether the woman reported seeking any infertility treatment. These results show that the mandate itself has no statistically significant effect on reports of seeking medical help. However, the coefficient on the three-way interaction of mandate, age at least 30 , and at least some college is 0.041 and is statistically significant at the

${ }^{19}$ The NSFG is a complex sample survey. Although all waves of the NSFG used were designed to provide data that were nationally representative of the U.S. female population aged 15-44, there have been numerous changes in sample design over time. In particular, different surveys oversampled different groups (e.g., black women in all NSFG waves, but Hispanic women in only 1995 and 2002, and teen women in only 1982). As a result, we use the population weights provided by the NSFG to ensure that the results are population representative. 
$5 \%$ level. This suggests that for highly educated older women, living in a mandate state is associated with a 4.1 percentage point increase in the probability of ever having sought medical help to get pregnant or avoid miscarriage. The magnitude of this effect is large, given the prereform means of around $15 \%$ of all women and $23 \%$ of more-educated women aged 30 and older in nonmandate states who ever sought such help.

We next separate these results into those for women who used medical help to get pregnant (column 2) and those for women who used medical help to avoid miscarriage (column 3). The entire effect found in column 1 is due to those who received medical help to get pregnant: the estimated coefficient on the three-way interaction is similar in both magnitude and statistical significance to the original coefficient. The estimated effect of the three-way interaction on help to avoid miscarriage is much smaller in magnitude and not statistically different from zero. ${ }^{20}$ Another way to get a sense of the magnitude of these effects is to normalize them by the baseline mean, which translates them into a percentage increase from the baseline. The bottom two rows of the table report the baseline mean of the relevant dependent variable for more-educated women aged 30 and older in no-mandate states and the three-way interaction effect measured as a share of this baseline. This suggests that the estimated effects of the mandates on older, more-educated women are considerably larger as a share of the baseline

${ }^{20}$ The coefficient on medical help to get pregnant has a $95 \%$ confidence interval of $[0.009$, 0.072], which excludes the point estimate for medical help to prevent miscarriage. Similarly, the upper bound for the $95 \%$ confidence interval for the miscarriage variable coefficient excludes the coefficient on help to get pregnant. We cannot perform a seemingly unrelated regression test, since women may report medical help to get pregnant or medical help to avoid miscarriage, or both. 
for medical help to get pregnant (24\%) compared with medical help to avoid miscarriage (8\%). This is as expected: the miscarriage variable should respond only indirectly to the mandates (e.g., if women who use infertility treatment conceive but are more likely to miscarry), so any effect of infertility insurance mandates on the miscarriage help variable should be smaller in magnitude than the effect on help to get pregnant.

The two-way mandate interactions in column 2 (mandate $\times 30$ and older, mandate $\times$ some college) are negative and statistically significant, which may be surprising, given that the mandate should lower costs for anyone affected by it. ${ }^{21}$ However, even a variable like "ever sought medical help to get pregnant" includes a wide variety of treatments, some of which may be less relevant in the presence of mandates (e.g., tubal surgery). Thus, we also explore the use of specific treatments in Table 5.

In Table 5, we look separately at different types of infertility treatments: use of ovulationinducing drugs, use of artificial insemination, use of IVF, testing (separately by testing of the female and of the male), tubal surgery, and some other treatment. Recall that most individuals who receive infertility proceed through a hierarchical process. Therefore, most individuals who receive ARTs like IVF will have already received lower-level treatments such as ovulationinducing drugs (as shown in Table 2). The estimated coefficient for $\beta_{7}$, our key variable of interest, is positive and statistically significant for the use of ovulation-inducing drugs, suggesting that mandates led to a 2 percentage point increase in use of these drugs for older

${ }^{21} \mathrm{We}$ also explored regressions restricted to age and education subgroups to be sure that our significant results are not being driven by these negative effects for some subgroups that one might expect not to be affected. Results are discussed in Tables 3 and 4 of the online appendix posted at Bitler's website. 
women with some college. This coefficient is not statistically different from the coefficients on testing of either the male or the female (neither of which is significant), which also suggest in each case a mandate effect of nearly 2 percentage points among older college-educated women. However, the effect of mandates on the use of ovulation-inducing drugs for older, more-educated women is considerably larger as a share of pre-mandate use than the effect on testing. A 2 percentage point increase in use of ovulation-inducing drugs with mandates reflects a $32 \%$ increase from a baseline level of use of $6.2 \%$ of women aged 30 and older with some college, compared with a $24 \%$ increase in the use of testing for females or males from a baseline level of use of $7.5 \%$ for female testing or $6.8 \%$ for male testing.

These effects are quite large in magnitude as a share of pre-mandate means. However, evidence suggests that unmet demand for infertility treatments in the United States is quite large. For example, in some European countries, where the government is much more likely to cover infertility treatment, utilization rates for ARTs are considerably higher than in the United States. Nyboe Andersen et al. (2008) reported that ART procedures in Denmark were associated with $4.2 \%$ of live births in 2004, compared with about $1.2 \%$ in the United States (Martin et al. 2006; Wright et al. 2007). The CDC reports that $20 \%$ of women have their first child after they reach age 35 , and notes that among couples in which the woman is older than 35 , one-third face an infertility problem (http://www.cdc.gov/reproductivehealth/Infertility/). Connolly et al. (2009) used the introduction of a 50\% copay for patients in Germany to estimate a price elasticity of demand, using a pre-post design. They found an elasticity of -0.36 for IVF. Taken together, this 
evidence suggests that coverage of these expensive therapies could lead to substantive increases in demand. ${ }^{22}$

Turning to the remaining specific treatments, we note that although not significant, the effect for artificial insemination is also positive and large as a share of the baseline. Use of IVF is not estimated to increase, but so few women report use of IVF in the NSFG that it would be surprising if we were able to discern any effects. In addition, the mandates have a small negative effect on the probability that a woman reports tubal surgery (although this effect is not statistically different from zero). It is plausible that there could be little change or even a decrease in tubal surgeries. First, evidence suggests that under an insurance plan that specifically excluded infertility treatment, nonnegligible fractions of claims paid for certain tubal and other surgeries were actually infertility related (Blackwell and Mercer 2000; Jones and Allen 2009). Second, as mentioned earlier, some evidence suggests that IVF and tubal surgeries could be seen as somewhat substitutable (Gocial 1995; Practice Committee of the American Society of Reproductive Medicine 2008).

The regressions on specific treatments also provide some insight into the negative and significant two-way interactions in Table 4. None of the two-way interactions for expensive treatments that are difficult to have reimbursed in the absence of infertility coverage are

${ }^{22}$ Our findings cannot determine whether mandates hasten fertility for women who would have children anyway; allow women to conceive who would not be able to otherwise; or create a form of moral hazard in which they encourage women to wait longer to start trying to conceive, relying on infertility treatment as insurance. Although these are important issues, the NSFG data, despite their many advantages, do not contain information on when women start trying to conceive, how long they had treatment, or whether the treatment itself resulted in a live birth. 
significant at the $5 \%$ level. The negative and statistically significant "mandate $\times 30$ and older" effect seen in Table 4, column 2, for any medical help to get pregnant is entirely driven by a decrease in the residual category of other treatment. The negative "mandate $\times$ some college" effect from Table 4 for medical help to get pregnant is associated with a small decrease in ovulation-inducing drugs (significant only at the 10\% level) and a slightly larger decrease in male testing (significant at the $1 \%$ level).

As described previously, the mandates differ along several dimensions. First, some mandates require that infertility treatments be covered, while others require only that coverage be offered. In Panel A of Tables 6 and 7, we break out cover mandates from offer mandates. Focusing first on column 2 of Table 6 , the broad indicator of whether a woman received any medical help to get pregnant shows similar effects of cover and offer mandates on utilization of services. The estimated coefficients for the two types of regressions are not statistically different. For the IVF versus no-IVF mandates, the effect of mandates that include IVF is twice the magnitude of the effect of mandates that exclude it (although the coefficients are not statistically different; the $F$ statistic for the two coefficients being the same is 1.14, with a $p$ value of .291 for the two-sided test and .146 for the one-sided test that the IVF coefficient is smaller than the noIVF coefficient).

However, the estimated effects of the different types of mandates are more striking when we examine the more detailed breakdown of treatments by type, in Table 7 . The estimated coefficients of cover mandates on ovulation-inducing drugs, artificial insemination, and testing of the female are positive and statistically significant. Cover mandates have a larger effect on the more expensive treatments of ovulation-inducing drugs than do offer mandates ( $F$ statistic is 1.77, with a $p$ value of .189 for the two-sided test and .095 for the one-sided test that the cover 
coefficient is smaller than the offer coefficient) and artificial insemination ( $F$ statistic is 3.03 , with $p$ value of .088 for the two-sided test and .044 for the one-sided test). The significant effects for the offer mandates seen in Table 7 come entirely from the residual other treatment category. ${ }^{23}$ In Panel B, we separate mandates that include IVF from those that do not. Again, IVF mandates have a statistically significant and positive effect on ovulation-inducing drugs. While the point estimate for the IVF mandates is usually larger than that for the no-IVF mandates, the coefficients are not statistically different from each other (even with one-sided tests). Again, we estimate no impact on IVF, but this is likely a consequence of the small numbers of women reporting IVF in our population data.

\section{Robustness}

We also estimated a number of robustness tests, including specifications in which mandate variables are allowed to vary by time since implementation, and specifications estimated on various subsamples. Some of these results are available in Online Resource 1, and others are available on request. In general, the effects are consistent with our main results in Tables 4-5, with largest effects for ovulation-inducing drugs and artificial insemination.

\section{Discussion and Conclusion}

Previous evidence concerning the effect of various health insurance mandates suggests that many such mandates have little impact on health care utilization. In this article, we pool data from waves of the National Survey of Family Growth to determine whether mandates for infertility treatment affect the use of infertility treatment among women aged 15-44. Our results suggest that state-level mandates related to coverage of infertility treatment are associated with a

\footnotetext{
${ }^{23}$ One possibility is that in offer states, women receive advice but then realize that they are not covered for more-expensive treatments and thus stop treatment.
} 
substantial and statistically significant increase in utilization of services, with effects being largest among a subgroup of older, more-educated women. Among specific types of infertility treatments, we find the largest effects on ovulation-inducing drugs and artificial insemination. These findings provide some of the only evidence available about the use of non-ART infertility treatments. In addition, they provide evidence on population use of treatments, and unlike recent work examining fertility, they include effects for women who may never successfully have children. For example, of the women in the NSFG who obtained any medical help to get pregnant, fully $28 \%$ of all women and $25 \%$ of older highly educated women did not have a first birth after their first infertility visit. These fractions provide a possible upper bound on the share of women who do not succeed in having a live birth despite their use of treatment. ${ }^{24}$

${ }^{24}$ Some of these women with no first birth are likely in the middle of treatment and may yet have a child. This is an upper bound on the share of women who are unsuccessful despite obtaining infertility treatment. If we limit this calculation to those women who had no first birth after their first infertility treatment and have not had a visit for infertility treatment in the past year, assuming that these women might be the most likely to have given up trying to conceive, we see that $14 \%$ of all women and $15 \%$ of the older, more-educated women fall into this category. Of the remaining women, $43 \%$ of all women and $46 \%$ of the older, more-educated women had a first birth after their first visit; and $29 \%$ of both sets of women had already had a first birth before the first visit and may therefore have been seeking treatment for secondary infertility. We cannot determine the outcomes for the women with any first birth before their first visit. We have not further examined these timing variables because they are reported only in the last two waves of the NSFG. 
One potential concern with our results is that the mandates could be correlated with broader trends in fertility, and therefore our estimated mandate effects could be picking up these broader trends. Our results suggest that, as expected, the mandates have the greatest effect on the more expensive and less easily hidden types of treatment and that help to prevent miscarriage is largely unaffected by the mandates. Both of these findings lend confidence to our interpretation of the results.

An implication of our findings is that subgroup heterogeneity is likely to be important in the analysis of the utilization and health impacts of various health insurance mandates. This is particularly true given that most health insurance mandates apply to only a share of privatesector employees. Because mandates are enacted to affect utilization of services and, ultimately, health outcomes, understanding why certain mandates affect these variables is important for understanding policy efficacy. One possible explanation for our findings of a utilization effect, when few of these effects have been found in the broader mandate literature, is that in the case of infertility treatment, individuals who are most likely to demand services (women who are older and highly educated) are also most likely to be affected by the mandate because of their higher probability of having private health insurance. For many other mandates, these two populations may not be the same. In those cases, affecting health outcomes may require other policy interventions.

Acknowledgments Bitler gratefully acknowledges financial support from the National Institute of Child Health and Human Development (NICHD) (R03 HD046485). Schmidt gratefully acknowledges financial support from NICHD (R03 HD047544). This work was begun while Bitler was at the RAND Corporation. All errors or omissions are our own. We thank Tom Buchmueller, Kitt Carpenter, Stacy Dickert-Conlin, Tracy Gordon, Steven Haider, Mireille 
Jacobson, Darius Lakdawalla, Kenneth Land, Purvi Sevak, Kosali Simon, two anonymous referees and seminar participants at Michigan State University and the Center for Studies in Demography and Ecology at the University of Washington for helpful comments, and Chris Rogers and Anjani Chandra for their generous assistance with the NSFG data.

\section{References}

Acs, G., Long, S. H., Marquis, M. S., \& Short, P. F. (1996). Self-insured employer health plans: Prevalence, profile, provisions, and premiums. Health Affairs, 15, 266-278.

Agency for Healthcare Research and Quality, Center for Financing, Access and Cost Trends. (2005). 2003 Medical Expenditure Panel Survey-Insurance Component Table II.D.1(2003) Average Total Family Premium (in dollars) per enrolled employee at private-sector establishments that offer health insurance by firm size and state: United States, 2003. Retrieved from http://meps.ahrq.gov/mepsweb/data_stats/summ_tables/insr/state/series_2/2003/tiid1.htm

American Society of Reproductive Medicine (ASRM). (2003). Patient fact sheet: Frequently asked questions about infertility. Retrieved from http://www.asrm.org/awards/index.aspx?id=3012

Bao, Y., \& Sturm, R. (2004). The effects of state mental health parity legislation in perceived quality of insurance coverage, perceived access to care, and use of mental health specialty care. Health Services Research, 39, 1361-1378.

Bitler, M. (2010). Effects of increased access to infertility treatment on infant and child health outcomes: Evidence from health insurance mandates. Unpublished Manuscript, Department of Economics, University of California-Irvine. 
Bitler, M., \& Carpenter, C. (2011). Insurance mandates and mammography. National Bureau of Economic Research Working Paper 16669.

Bitler, M., \& Schmidt, L. (2006). Health disparities and infertility: Impacts of state-level insurance mandates. Fertility and Sterility, 85, 858-865.

Bitler, M., \& Zavodny, M. (2010). The Effect of Medicaid Eligibility Expansions on Fertility. Social Science and Medicine, 71, 918-924.

Blackburn, M. L., Bloom, D., \& Neumark, D. (1993). Fertility timing, wages, and human capital. Journal of Population Economics, 93, 1-30.

Blackwell, R. E., and the William M. Mercer Actuarial Team. (2000). Hidden costs of infertility treatment in employee health benefits plans. American Journal of Obstetrics and Gynecology, 182, 891-895.

Buckles, K. (2006). Stopping the biological clock: Fertility therapies and the career/family tradeoff. Unpublished Manuscript, Department of Economics, University of Notre Dame.

Bunce, V.C. \& Wieske, J.P. (2010). Health insurance mandates in the states. Council for Affordable Health Insurance Policy Brief.

Bundorf, M. K., Chun, N., Goda, G. S., \& Kessler, D. P. (2009). Do markets respond to quality information? The case of fertility clinics. Journal of Health Economics, 28, 718-727.

Bundorf, M. K., Henne, M., \& Baker, L. (2008). Mandated health insurance benefits and the utilization and outcomes of infertility treatment (NBER Working Paper No. 12820). Cambridge, MA: National Bureau of Economic Research.

Chambers, G. M., Sullivan, E. A., Ishihara, O., Chapman, M. G., \& Adamson, G. D. (2009). The economic impact of assisted reproductive technology: A review of selected developed countries. Fertility and Sterility, 91, 2281-2294. 
Chandra, A., \& Stephen, E. H. (2005, March). Infertility and medical care for infertility: Trends and differentials in national self-reported data. Presented at the NIH Conference on Health Disparities and Infertility, Bethesda, Maryland.

Collins, J. (2001). Cost-effectiveness of IVF. Seminars in Reproductive Medicine, 19, 279-289.

Conley, T. G., \& Taber, C. R. (2011). Inference with "difference in differences" with a small number of policy changes. Review of Economics and Statistics, 93,113-125.

Connolly, M. P., Griesinger, G., Ledget, W., \& Postma, M. J. (2009). The impact of introducing patient co-payments in Germany on the use of IVF and ICSI: A price elasticity of demand assessment. Human Reproduction, 24, 2796-2800.

Gabel, J., Jensen, G. A., Hawkins, S. (2003). Self-insurance in times of growing and retreated managed care. Health Affairs, 22, 202-210.

Gelbach, J. B., Klick, J., \& Wexler, L. (2009). Passive discrimination: When does it make sense to pay too little? University of Chicago Law Review, 76, 797-857.

Gleicher, N. (2000). Cost-effective infertility care. Human Reproduction Update, 6, 190-199.

Gocial, B. (1995). Primary therapy for tubal disease: Surgery versus IVF. International Journal of Fertility and Menopausal Studies, 40, 297-302.

Gruber, J. (1994). State-mandated benefits and employer-provided health insurance. Journal of Public Economics, 55, 433-464.

Hamilton, B., \& McManus, B. (2005). Infertility treatment markets: The effects of competition and policy. Unpublished manuscript, Olin School of Business, Washington University, St. Louis, MO.

Henne, M. B., \& Bundorf, M. K. (2008). Insurance mandates and trends in infertility treatments. Fertility and Sterility, 89, 66-73. 
Jain, T., Harlow, B. L., \& Hornstein, M. D. (2002). Insurance coverage and outcomes of in vitro fertilization. New England Journal of Medicine, 347, 661-666.

Jensen, G. A., Rost, K., Burton, R. P. D., \& Bulycheva, M. (1998). Mental health insurance in the 1990s: Are employers offering less to more? Health Affairs, 17, 201-208.

Jones, H. W. Jr., \& Allen, B. D. (2009). Strategies for designing an efficient insurance fertility benefit: A 21st century approach. Fertility and Sterility, 91, 2295-2297.

Kaestner, R., \& Simon, K. I. (2002). Labor market consequences of state health insurance regulation. Industrial and Labor Relations Review, 56, 136-159.

Liu, Z., Dow, W. H., \& Norton, E. C. (2004). Effect of drive-through delivery laws on postpartum length of stay and hospital charges. Journal of Health Economics, 23, 129155.

Lleras-Muney, A., \& Dehejia, R. (2004). Booms, Busts and Babies' Health. Quarterly Journal of Economics, 119, 1091-1130.

Martin, J. A., Hamilton, B. E., Sutton, P. D., Ventura, S. J., Menacker, F., \& Kirmeyer, S. (2006). Births: Final data for 2004 (National Vital Statistics Reports 55(1)). Hyattsville, MD: National Center for Health Statistics.

Mathews, T. J., \& Hamilton, B. E. (2002). Mean age of mother: 1970-2000 (National Vital Statistics Reports 51(1)). Hyattsville, MD: National Center for Health Statistics.

Menken, J. (1985). Age and fertility: How late can you wait? Demography, 22, 469-483.

Miller, A. R. (2011). The effects of motherhood timing on career path. Journal of Population Economics 24, 1071-1100. 
Mookim, P. G., Ellis, R. P., \& Kahn-Lang, A. (2008). Infertility treatment, ART and IUI procedures and delivery outcomes: How important is selection? Unpublished manuscript, Department of Economics, Boston University, Boston, MA.

Neumann, P. J., Gharib, S. D., \& Weinstein, M. C. (1994). The cost of a successful delivery with in vitro fertilization. New England Journal of Medicine, 331, 239-243.

New York Times. (2001, September 1). Insurers offering pregnancy benefits now must cover fertility. (http://www.nytimes.com/2001/09/01/nyregion/insurers-offering-pregnancybenefits-now-must-cover-fertility.html)

Nyboe Andersen, A., Goosens, V., Ferraretti, A. P., Bhattacharya, S., Felberbaum, R., de Mouzon, J., \& Nygren, K. G. (2008). Assisted reproductive technology in Europe, 2004: Results generated from European registers by ESHRE. Human Reproduction, 23, $756-$ 771.

Oyer, P. (2008). Salary or benefits? Research in Labor Economics, 28, 429-467.

Pacula, R. L., \& Sturm, R. (2000). Mental health parity legislation: Much ado about nothing. Health Services Research, 35, 263-275.

Practice Committee of the American Society of Reproductive Medicine. (2008). The role of tubal reconstructive surgery in the era of assisted reproductive technologies. Fertility and Sterility, 90(Suppl.t 3), S250-S253.

RESOLVE. (2003). Insurance coverage of infertility treatments. Bethesda MD: RESOLVE: The National Infertility Association.

Rothschild, M., \& Stiglitz, J. E. (1976). Equilibrium in competitive insurance markets: An essay on the economics of imperfect information. Quarterly Journal of Economics, 90, 629649. 
Schmidt, L. (2005). Effects of infertility insurance mandates on fertility. Unpublished manuscript, Department of Economics, Williams College, Williamstown, MA.

Schmidt, L. (2007). Effects of infertility insurance mandates on fertility. Journal of Health Economics, 26, 431-446.

Stephen, E. H., \& Chandra, A. (2000). Use of infertility services in the United States: 1995. Family Planning Perspectives, 32, 132-137.

Weinstein, M., Wood, J. W., Stoto, M. A., \& Greenfield, D. D. (1990). Components of agespecific fecundability. Population Studies, 44, 447-467.

William M. Mercer Company. (1997). Women's health issues: Infertility as a covered benefit.

Wright, V. C., Schieve, L. A., Reynolds, M. A., \& Jeng, G. (2003). Assisted reproductive technology surveillance-United States 2000. MMWR Surveillance Summaries, 52(SS09), 1-16.

Wright, V. C., Chang, J., Jeng, G., Chen, M., \& Macaluso, M. (2007). Assisted reproductive technology surveillance-United States, 2004. MMWR Surveillance Summaries 56(SS06), 1-22. 
Table 1 States with mandated infertility insurance

\begin{tabular}{llll}
\hline & $\begin{array}{l}\text { Year } \\
\text { Law } \\
\text { Enacted }\end{array}$ & $\begin{array}{l}\text { Mandate to } \\
\text { Cover/Offer to } \\
\text { Cover }\end{array}$ & $\begin{array}{l}\text { IVF } \\
\text { Covered }\end{array}$ \\
\hline Arkansas & $1987^{\mathrm{a}}$ & Cover & Yes \\
California & 1989 & Offer & No \\
Connecticut & $1989^{\mathrm{b}}$ & Offer & Yes \\
Hawaii & 1987 & Cover & Yes \\
Illinois & 1991 & Cover & Yes \\
Louisiana & 2001 & Cover & No \\
Maryland & 1985 & Cover & Yes \\
Massachusetts & 1987 & Cover & Yes \\
Montana & 1987 & Cover & Yes \\
New Jersey & 2001 & Cover & Yes \\
New York & $1990^{\mathrm{c}}$ & Cover & No \\
Ohio & $1990^{\mathrm{d}}$ & Cover & Yes \\
Rhode Island & 1989 & Cover & Yes \\
Texas & 1987 & Offer & Yes \\
West Virginia & $1977^{\mathrm{e}}$ & Cover & No \\
\hline
\end{tabular}

Source: Schmidt (2007).

${ }^{\text {a }}$ Some coverage for IVF was first required in 1987. The law was revised in 1991 to set maximum and minimum benefit levels and to establish standards for determining whether a policy or certificate must include coverage (see Schmidt 2005: Appendix A).

${ }^{\mathrm{b}}$ In 2005, Connecticut changed their offer mandate to a cover mandate.

${ }^{c}$ In 2002, New York passed a revised law that clarified the 1990 legislation and appropriated \$10 million to a pilot project to help pay for IVF for a small number of individuals.

${ }^{\mathrm{d}}$ The original 1991 law did not specifically exclude IVF. But in1997, the state superintendent of insurance stated that IVF, GIFT, and ZIFT were not essential for the protection of an individual's health and were therefore not subject to mandated coverage. We code Ohio as an IVF state through 1997.

${ }^{\mathrm{e}}$ In 2001, the law was amended to mandate that HMOs must cover infertility treatment only as a "preventative service" benefit (thus, excluding IVF). 
Table 2 Share of women obtaining one treatment who had each of the other treatments, all women, pooled NSFG data

\begin{tabular}{|c|c|c|c|c|c|c|c|c|}
\hline & $\begin{array}{l}\text { Ovulation } \\
\text {-Inducing } \\
\text { Drugs }\end{array}$ & $\begin{array}{l}\text { Artificial } \\
\text { Insemination }\end{array}$ & IVF & $\begin{array}{l}\text { Testing } \\
\text { of } \\
\text { Female } \\
\end{array}$ & $\begin{array}{l}\text { Testing } \\
\text { of Male }\end{array}$ & $\begin{array}{l}\text { Tubal } \\
\text { Surgery }\end{array}$ & $\begin{array}{l}\text { Any } \\
\text { Other } \\
\text { Treatmen } \\
\mathrm{t}\end{array}$ & $\begin{array}{l}\text { Other } \\
\text { Treatmen } \\
\mathrm{t} \text { and Not } \\
1-6\end{array}$ \\
\hline \multicolumn{9}{|c|}{ A. Share of Women in Row Group Getting Treatment } \\
\hline All women & 0.034 & 0.008 & 0.002 & 0.039 & 0.035 & 0.013 & 0.076 & 0.038 \\
\hline Women who got help to get pregnant & 0.337 & 0.081 & 0.017 & 0.388 & 0.351 & 0.126 & 0.763 & 0.377 \\
\hline \multicolumn{9}{|c|}{ B. Share of Women Getting Column Treatment Who Also Used: } \\
\hline Ovulation-inducing drugs & 1 & 0.71 & 0.65 & 0.54 & 0.49 & 0.49 & 0.30 & 0 \\
\hline Artificial insemination & 0.17 & 1 & 0.46 & 0.18 & 0.17 & 0.17 & 0.08 & 0 \\
\hline IVF & 0.03 & 0.10 & 1 & 0.04 & 0.04 & 0.06 & 0.02 & 0 \\
\hline Testing of female & 0.62 & 0.85 & 0.80 & 1 & 0.75 & 0.62 & 0.36 & 0 \\
\hline Testing of male & 0.52 & 0.75 & 0.79 & 0.68 & 1 & 0.53 & 0.34 & 0 \\
\hline Tubal surgery & 0.18 & 0.27 & 0.42 & 0.20 & 0.19 & 1 & 0.11 & 0 \\
\hline Any other treatment & 0.69 & 0.78 & 0.78 & 0.70 & 0.74 & 0.69 & 1 & 1 \\
\hline Other treatment and not rows $1-6$ & 0 & 0 & 0 & 0 & 0 & 0 & 0.48 & 1 \\
\hline
\end{tabular}

Notes: Shown are weighted averages among various samples of women who have ever had sex after menarche for various outcomes. Panel A contains the share of the women in the row sample who obtained the treatments in the column headings. Panel B contains the share of women getting the treatment in the column heading who also got the treatment in the row label. Treatments are not mutually exclusive (with the exception of the last row/column "other treatment none of the specific ones" which is mutually exclusive with the specific treatments).

"Other treatment" in some years includes advice on timing sex or timing use of birth control or other advice and other surgeries (e.g., fibroids). Data are from pooled 1982, 1988, 1995, and 2002 waves of the NSFG. Rounding for various rows was done independently. 
Table 3 Summary statistics for use of infertility treatment and fertility outcomes, all women and by group, pooled NSFG data

\begin{tabular}{|c|c|c|c|c|c|}
\hline & \multirow[b]{2}{*}{$\begin{array}{l}\text { All } \\
\text { Women }\end{array}$} & \multicolumn{2}{|c|}{ Age Under 30} & \multicolumn{2}{|c|}{ Age 30 and Older } \\
\hline & & $\begin{array}{l}\text { No } \\
\text { College } \\
\end{array}$ & $\begin{array}{l}\begin{array}{l}\text { Some } \\
\text { College }\end{array} \\
\end{array}$ & $\begin{array}{l}\text { No } \\
\text { College } \\
\end{array}$ & $\begin{array}{l}\begin{array}{l}\text { Some } \\
\text { College }\end{array} \\
\end{array}$ \\
\hline \multirow[t]{2}{*}{ Ever had any infertility treatment (to get pregnant or prevent miscarriage) } & 0.145 & 0.073 & 0.088 & 0.162 & 0.228 \\
\hline & $(0.002)$ & $(0.005)$ & $(0.004)$ & $(0.004)$ & $(0.004)$ \\
\hline \multirow[t]{2}{*}{ Ever had treatment to help get pregnant } & 0.100 & 0.048 & 0.048 & 0.112 & 0.168 \\
\hline & $(0.002)$ & $(0.003)$ & $(0.004)$ & $(0.003)$ & $(0.003)$ \\
\hline \multirow[t]{2}{*}{ Ever had treatment to prevent miscarriage } & 0.068 & 0.048 & 0.033 & 0.073 & 0.103 \\
\hline & $(0.001)$ & $(0.003)$ & $(0.003)$ & $(0.003)$ & $(0.003)$ \\
\hline \multicolumn{6}{|l|}{ Type of treatments to help get pregnant (not mutually exclusive) } \\
\hline \multirow[t]{2}{*}{ Ovulation-inducing drugs } & 0.034 & 0.014 & 0.014 & 0.034 & 0.065 \\
\hline & $(0.001)$ & $(0.002)$ & $(0.002)$ & $(0.002)$ & $(0.002)$ \\
\hline \multirow[t]{2}{*}{ Artificial insemination } & 0.008 & 0.001 & 0.002 & 0.008 & 0.019 \\
\hline & $(0.001)$ & $(0.001)$ & $(0.001)$ & $(0.001)$ & $(0.001)$ \\
\hline \multirow[t]{2}{*}{ In vitro fertilization } & 0.002 & 0.0002 & 0.0002 & 0.0008 & 0.0049 \\
\hline & $(0.0002)$ & $(0.0005)$ & $(0.0005)$ & $(0.0004)$ & $(0.0004)$ \\
\hline \multirow[t]{2}{*}{ Woman tested for infertility } & 0.039 & 0.013 & 0.013 & 0.040 & 0.077 \\
\hline & $(0.001)$ & $(0.002)$ & $(0.003)$ & $(0.002)$ & $(0.002)$ \\
\hline \multirow[t]{2}{*}{ Man tested for infertility } & 0.035 & 0.014 & 0.011 & 0.036 & 0.069 \\
\hline & $(0.001)$ & $(0.002)$ & $(0.002)$ & $(0.002)$ & $(0.002)$ \\
\hline \multirow[t]{2}{*}{ Surgery to correct blocked Fallopian tubes } & 0.013 & 0.005 & 0.003 & 0.016 & 0.023 \\
\hline & $(0.001)$ & $(0.001)$ & $(0.001)$ & $(0.001)$ & $(0.001)$ \\
\hline \multirow[t]{2}{*}{ Some other treatment } & 0.038 & 0.023 & 0.023 & 0.044 & 0.055 \\
\hline & $(0.001)$ & $(0.002)$ & $(0.003)$ & $(0.002)$ & $(0.002)$ \\
\hline \multirow[t]{2}{*}{ Private insurance paid for treatment ${ }^{\mathrm{a}}$} & 0.070 & 0.020 & 0.030 & 0.073 & 0.126 \\
\hline & $(0.002)$ & $(0.004)$ & $(0.005)$ & $(0.004)$ & $(0.003)$ \\
\hline \multirow[t]{2}{*}{ No private insurance to pay for treatment ${ }^{\mathrm{a}}$} & 0.023 & 0.015 & 0.007 & 0.025 & 0.035 \\
\hline & $(0.001)$ & $(0.002)$ & $(0.003)$ & $(0.002)$ & $(0.002)$ \\
\hline$N$ & 30,149 & 11,328 & 6,182 & 8,973 & 8,425 \\
\hline
\end{tabular}




\begin{abstract}
Notes: Shown are weighted averages among women who have ever had sex after menarche for various outcomes. The means are for the sample of women described in the column labels. Only women who reported getting medical help to get pregnant were asked about the types of treatment they received. Treatments are not mutually exclusive. "Other treatment" in some years includes advice on timing sex or timing use of birth control or other advice. Data are from pooled 1982, 1988, 1995, and 2002 waves of the NSFG. Rounding for various rows was done independently.

${ }^{a}$ Questions on how they paid for the medical help to get pregnant were asked only in the 1995 and 2002 waves of the NSFG.
\end{abstract}


Table 4 Determinants of any infertility treatment, medical help to get pregnant, and medical help to avoid miscarriage

\begin{tabular}{|c|c|c|c|}
\hline & $\begin{array}{l}\text { Any infertility } \\
\text { treatment }\end{array}$ & $\begin{array}{l}\text { Medical } \\
\text { help to get } \\
\text { pregnant }\end{array}$ & $\begin{array}{l}\text { Medical help to } \\
\text { avoid miscarriage }\end{array}$ \\
\hline \multirow[t]{2}{*}{ Any Mandate } & 0.007 & 0.004 & 0.002 \\
\hline & $(0.011)$ & $(0.010)$ & $(0.007)$ \\
\hline \multirow[t]{2}{*}{ Age 30 and Older } & $0.079 * *$ & $0.072 * *$ & $0.022 * *$ \\
\hline & $(0.007)$ & $(0.007)$ & $(0.005)$ \\
\hline \multirow[t]{2}{*}{ Some College } & $-0.016^{*}$ & -0.0001 & $-0.015 * *$ \\
\hline & $(0.007)$ & $(0.005)$ & $(0.005)$ \\
\hline \multirow[t]{2}{*}{ Mandate $\times 30$ and Older } & -0.021 & $-0.027 *$ & 0.003 \\
\hline & $(0.013)$ & $(0.010)$ & $(0.009)$ \\
\hline \multirow[t]{2}{*}{ Mandate $\times$ Some College } & -0.013 & $-0.015^{*}$ & -0.004 \\
\hline & $(0.009)$ & $(0.007)$ & $(0.008)$ \\
\hline \multirow[t]{2}{*}{30 and Older $\times$ Some College } & $0.071 * *$ & $0.046^{* *}$ & $0.043 * *$ \\
\hline & $(0.012)$ & $(0.010)$ & $(0.008)$ \\
\hline \multirow[t]{2}{*}{ Mandate $\times \geq 30 \times$ Some College } & $0.041^{*}$ & $0.041^{*}$ & 0.008 \\
\hline & $(0.018)$ & $(0.016)$ & $(0.013)$ \\
\hline \multicolumn{4}{|l|}{ Mean, No Mandate in Effect, } \\
\hline Women $\geq 30$ and Some College & 0.228 & 0.170 & 0.100 \\
\hline \multicolumn{4}{|l|}{ Three-Way Interaction as Share } \\
\hline \multicolumn{4}{|c|}{$\begin{array}{l}\text { Notes: Shown are coefficients from least squares regressions of the determinants of } \\
\text { ever having had various types of infertility treatments. Each column presents results } \\
\text { from a single regression. Regressions are weighted, with standard errors clustered at } \\
\text { the state level in parentheses. Specifications include state and year of interview fixed } \\
\text { effects and individual demographic and state-by-year level demographic, policy, and } \\
\text { economic controls. Data are from pooled } 1982,1988,1995 \text {, and } 2002 \text { waves of the } \\
\text { NSFG. The sample is all women who ever had sex after menarche. Bottom two rows } \\
\text { present pre-mandate mean of dependent variable for women } \geq 30 \text { with some college } \\
\text { and the three-way interaction effect (coefficient on mandate } \times \geq 30 \times \text { some college) as a }\end{array}$} \\
\hline
\end{tabular}


share of the baseline mean.
${ }^{\dagger} p<.10 ; * p<.05 ; * * p<.01$ 
Table 5 Determinants of specific medical treatments to help get pregnant

\begin{tabular}{|c|c|c|c|c|c|c|c|}
\hline & $\begin{array}{l}\text { Ovulation- } \\
\text { inducing } \\
\text { drugs }\end{array}$ & $\begin{array}{l}\text { Artificial } \\
\text { insemination }\end{array}$ & IVF & $\begin{array}{l}\text { Testing of } \\
\text { female }\end{array}$ & $\begin{array}{l}\text { Testing } \\
\text { of male }\end{array}$ & $\begin{array}{l}\text { Tubal } \\
\text { surgery }\end{array}$ & $\begin{array}{l}\text { Other } \\
\text { treatment }\end{array}$ \\
\hline \multirow[t]{2}{*}{ Any Mandate } & 0.001 & -0.0001 & 0.0008 & -0.005 & -0.003 & 0.0003 & 0.005 \\
\hline & $(0.004)$ & $(0.0029)$ & $(0.0012)$ & $(0.006)$ & $(0.006)$ & $(0.0028)$ & $(0.008)$ \\
\hline \multirow[t]{2}{*}{ Age 30 and Older } & $0.020 * *$ & $0.006 * *$ & 0.0004 & $0.027 * *$ & $0.022 * *$ & $0.010 * *$ & $0.026 * *$ \\
\hline & $(0.003)$ & $(0.001)$ & $(0.0006)$ & $(0.004)$ & $(0.004)$ & $(0.002)$ & $(0.006)$ \\
\hline \multirow[t]{2}{*}{ Some College } & -0.002 & -0.0006 & -0.0005 & -0.004 & -0.004 & -0.003 & 0.001 \\
\hline & $(0.003)$ & $(0.0012)$ & $(0.0003)$ & $(0.003)$ & $(0.003)$ & $(0.002)$ & $(0.003)$ \\
\hline \multirow[t]{2}{*}{ Mandate $\times 30$ and Older } & -0.004 & -0.0005 & 0.0002 & -0.008 & -0.002 & 0.0002 & $-0.013 *$ \\
\hline & $(0.005)$ & $(0.0027)$ & $(0.0006)$ & $(0.007)$ & $(0.007)$ & $(0.0029)$ & $(0.006)$ \\
\hline \multirow[t]{2}{*}{ Mandate $\times$ Some College } & $-0.008^{\dagger}$ & -0.001 & 0.0011 & -0.007 & $-0.010^{* *}$ & -0.001 & -0.002 \\
\hline & $(0.004)$ & $(0.002)$ & $(0.0010)$ & $(0.005)$ & $(0.004)$ & $(0.002)$ & $(0.005)$ \\
\hline \multirow[t]{2}{*}{30 and Older $\times$ Some College } & $0.026 * *$ & $0.008 * *$ & $0.0041^{* *}$ & $0.033 * *$ & $0.032 * *$ & $0.010 * * *$ & 0.008 \\
\hline & $(0.005)$ & $(0.003)$ & $(0.0011)$ & $(0.006)$ & $(0.006)$ & $(0.003)$ & $(0.007)$ \\
\hline \multirow[t]{2}{*}{ Mandate $\times \geq 30 \times$ Some College } & $0.020^{*}$ & 0.007 & -0.00002 & 0.018 & 0.016 & -0.002 & 0.011 \\
\hline & $(0.009)$ & $(0.005)$ & $(0.00216)$ & $(0.013)$ & $(0.011)$ & $(0.006)$ & $(0.009)$ \\
\hline \multicolumn{8}{|l|}{ Mean, No Mandate in Effect, Women } \\
\hline$\geq 30$ and Some College & 0.062 & 0.017 & 0.005 & 0.075 & 0.068 & 0.024 & 0.057 \\
\hline \multicolumn{8}{|l|}{ Three-Way Interaction as Share of } \\
\hline Mean & 0.32 & 0.41 & -0.004 & 0.24 & 0.24 & -0.08 & 0.19 \\
\hline \multicolumn{8}{|c|}{$\begin{array}{l}\text { Notes: Shown are coefficients from least squares regressions of the determinants of ever having had various types of infertility } \\
\text { treatments. Results in column } 6 \text { for outcome "other treatment" are for some treatment other than those in columns } 1-6 \text {. Each column } \\
\text { presents results from a single regression. Regressions are weighted, with standard errors clustered at the state level in parentheses. } \\
\text { Specifications include state and year of interview fixed effects and individual demographic and state-by-year level demographic, policy, } \\
\text { and economic controls. Data are from pooled } 1982,1988,1995 \text {, and } 2002 \text { waves of the NSFG. The sample is all women who ever had } \\
\text { sex after menarche. The bottom two rows present pre-mandate mean of dependent variable for women } \geq 30 \text { with some college and the } \\
\text { three-way interaction effect (coefficient on mandate } x \geq 30 \text { x some college) as a share of the baseline mean. } \\
{ }^{\dagger} p<.10 ;{ }^{*} p<.05 ; * * p .01\end{array}$} \\
\hline
\end{tabular}


Table 6 Determinants of any infertility treatment, medical help to get pregnant, and medical help to avoid miscarriage, by type of mandate

\begin{tabular}{|c|c|c|c|}
\hline & $\begin{array}{l}\text { Any Infertility } \\
\text { Treatment }\end{array}$ & $\begin{array}{l}\text { Medical Help to Get } \\
\text { Pregnant }\end{array}$ & $\begin{array}{l}\text { Medical Help } \\
\text { to Avoid } \\
\text { Miscarriage }\end{array}$ \\
\hline \multicolumn{4}{|c|}{ A. Mandate Varies by Whether Mandate Is to Cover or Offer } \\
\hline \multirow[t]{2}{*}{ Cover mandate $\times \geq 30 \times$ some college } & $0.055^{*}$ & 0.040 & $0.027^{\dagger}$ \\
\hline & $(0.027)$ & $(0.024)$ & $(0.015)$ \\
\hline \multirow[t]{2}{*}{ Offer mandate $\times \geq 30 \times$ some college } & $0.026^{\dagger}$ & $0.043 * *$ & -0.014 \\
\hline & $(0.014)$ & $(0.014)$ & $(0.009)$ \\
\hline$F$ statistic, test coefficients equal & 1.25 & 0.02 & 8.95 \\
\hline$p$ value, two-sided test & $(.269)$ & $(.900)$ & $(.004)$ \\
\hline$p$ value, one-sided test, null cover less than offer & {$[.135]$} & {$[.550]$} & {$[.002]$} \\
\hline \multicolumn{4}{|l|}{ B. Mandate Varies by Whether IVF Is Excluded or Not } \\
\hline \multirow[t]{2}{*}{ Mandate with IVF $x \geq 30 \times$ some college } & $0.049 *$ & $0.052 * *$ & 0.016 \\
\hline & $(0.021)$ & $(0.015)$ & $(0.020)$ \\
\hline \multirow[t]{2}{*}{ Mandate no IVF $\times \geq 30 \times$ some college } & 0.030 & 0.028 & -0.002 \\
\hline & $(0.025)$ & $(0.022)$ & $(0.016)$ \\
\hline$F$ statistic. test coefficients equal & 0.46 & 1.14 & 0.62 \\
\hline$p$ value, two-sided test & $(.499)$ & $(.291)$ & $(.435)$ \\
\hline$p$ value, one-sided test, null IVF less than no IVF & {$[.250]$} & {$[.146]$} & [.218] \\
\hline
\end{tabular}

Notes: Shown are coefficients from least squares regressions of the determinants of ever having had various types of infertility treatments. Each panel contains results with a different set of mandate education age interactions. Each column within panel presents results from a single regression. At the bottom of each panel, $F$ tests for equality of the coefficients shown are reported, along with $p$ values from two-sided tests in parentheses; $p$ values from a one-sided test of the null that the cover coefficient is less than the offer coefficient (panel A) or the null that the IVF-allowed coefficient is less than the no-IVF coefficient (panel B) are shown in brackets. Regressions are weighted, with standard errors clustered at the state level in parentheses. Specifications include state and year of interview fixed effects and individual demographic and state-by-year level demographic, policy, and economic controls. Data are from pooled 1982, 1988, 1995, and 2002 waves of the NSFG. The sample is all women who ever had sex after menarche.

${ }^{\dagger} p<.10 ;{ }^{*} p<.05 ; * * p<.01$ 
Table 7 Determinants of specific medical treatments to help get pregnant, by type of mandate

\begin{tabular}{|c|c|c|c|c|c|c|c|}
\hline & $\begin{array}{l}\text { Ovulation- } \\
\text { Inducing } \\
\text { Drugs }\end{array}$ & $\begin{array}{l}\text { Artificial } \\
\text { Insemination }\end{array}$ & IVF & $\begin{array}{l}\text { Testing of } \\
\text { Female }\end{array}$ & $\begin{array}{l}\text { Testing } \\
\text { of Male }\end{array}$ & $\begin{array}{l}\text { Tubal } \\
\text { Surgery }\end{array}$ & $\begin{array}{l}\text { Other } \\
\text { Treatment }\end{array}$ \\
\hline \multicolumn{8}{|c|}{ A. Mandate Varies by Whether Mandate Is to Cover or Offer } \\
\hline Cover mandate $\times \geq 30 \times$ some college & $\begin{array}{r}0.030^{*} \\
(0.014)\end{array}$ & $\begin{array}{r}0.012^{\dagger} \\
(0.006)\end{array}$ & $\begin{array}{r}0.001 \\
(0.003)\end{array}$ & $\begin{array}{r}0.034^{\dagger} \\
(0.017)\end{array}$ & $\begin{array}{r}0.025 \\
(0.016)\end{array}$ & $\begin{array}{l}-0.0002 \\
(0.0057)\end{array}$ & $\begin{array}{l}-0.005 \\
(0.009)\end{array}$ \\
\hline Offer mandate $\times \geq 30 \times$ some college & $\begin{array}{r}0.009 \\
(0.009)\end{array}$ & $\begin{array}{r}0.0006 \\
(0.0048)\end{array}$ & $\begin{array}{l}-0.001 \\
(0.001)\end{array}$ & $\begin{array}{r}-0.0005 \\
(0.007)\end{array}$ & $\begin{array}{r}0.005 \\
(0.0067)\end{array}$ & $\begin{array}{l}-0.003 \\
(0.008)\end{array}$ & $\begin{array}{r}0.029 * * \\
(0.007)\end{array}$ \\
\hline $\begin{array}{l}F \text { statistic, test coefficients equal } \\
p \text { value, two-sided test }\end{array}$ & $\begin{array}{r}1.77 \\
(.189)\end{array}$ & $\begin{array}{r}3.03 \\
(.088)\end{array}$ & $\begin{array}{r}0.47 \\
(.495)\end{array}$ & $\begin{array}{r}4.35 \\
(.042)\end{array}$ & $\begin{array}{r}1.77 \\
(.189)\end{array}$ & $\begin{array}{r}0.13 \\
(.722)\end{array}$ & $\begin{array}{r}18.96 \\
(.0001)\end{array}$ \\
\hline $\begin{array}{l}p \text { value, one-sided test, null cover less than } \\
\text { offer }\end{array}$ & {$[.095]$} & {$[.044]$} & {$[.248]$} & {$[.021]$} & {$[.095]$} & {$[.361]$} & {$[.99997]$} \\
\hline \multicolumn{8}{|c|}{ B. Mandate Varies by Whether IVF Is Excluded or Not } \\
\hline Mandate with IVF $\times \geq 30 \times$ some college & $\begin{array}{r}0.028^{* *} \\
(0.010)\end{array}$ & $\begin{array}{r}0.005 \\
(0.007)\end{array}$ & $\begin{array}{r}-0.0006 \\
(0.003)\end{array}$ & $\begin{array}{r}0.018 \\
(0.014)\end{array}$ & $\begin{array}{r}0.021 \\
(0.013)\end{array}$ & $\begin{array}{r}0.002 \\
(0.004)\end{array}$ & $\begin{array}{r}0.013 \\
(0.010)\end{array}$ \\
\hline Mandate no IVF $\times \geq 30 \times$ some college & $\begin{array}{r}0.011 \\
(0.013)\end{array}$ & $\begin{array}{r}0.008 \\
(0.005)\end{array}$ & $\begin{array}{r}0.0007 \\
(0.0018)\end{array}$ & $\begin{array}{r}0.015 \\
(0.018)\end{array}$ & $\begin{array}{r}0.01 \\
(0.013)\end{array}$ & $\begin{array}{l}-0.006 \\
(0.008)\end{array}$ & $\begin{array}{r}0.009 \\
(0.023)\end{array}$ \\
\hline$F$ statistic, test coefficients equal & 1.02 & 0.18 & 0.14 & 0.02 & 0.45 & 1.35 & 0.06 \\
\hline $\begin{array}{l}p \text { value, two-sided test } \\
p \text { value, one-sided test, null IVF less than no }\end{array}$ & $(.318)$ & $(.672)$ & $(.711)$ & $(.902)$ & $(.503)$ & $(.250)$ & $(.814)$ \\
\hline IVF & [.159] & {$[.664]$} & [.645] & {$[.451]$} & {$[.252]$} & {$[.125]$} & [.407] \\
\hline
\end{tabular}

Notes: Shown are coefficients from least squares regressions of the determinants of ever having had various types of infertility treatments.

Each panel contains results with a different set of mandate education age interactions. Each column within panel presents results from a single regression. At the bottom of each panel, $F$ tests for equality of the coefficients shown are reported, along with $p$ values from twosided tests in parentheses; $p$ values from a one-sided test of the null that the cover coefficient is less than the offer coefficient (panel A) or the null that the IVF-allowed coefficient is less than the no-IVF coefficient (panel B) are shown in brackets. Regressions are weighted, with standard errors clustered at the state level in parentheses. Specifications include state and year of interview fixed effects and individual demographic and state-by-year level demographic, policy, and economic controls. Data are from pooled 1982, 1988, 1995, and 2002 waves of the NSFG. The sample is all women who ever had sex after menarche.

${ }^{\dagger} p<.10 ; * p<.05 ; * * p<.01$ 